\title{
MÔ HÌNH NGHIÊN CỨU HEDPERF TRONG ĐÁNH GIÁ CHẤT LƯợNG ĐÀO TẠO - TİNH HUỐNG NGHIÊN CÚU: TRƯỜNG ĐẠI HỌC CÔNG NGHIỆP TP. HỒ CHÍ MINH
}

\author{
BÙI VĂN QUANG, BÙI VĂN DANH \\ Truờng Đại học Công nghiệp thành phố Hồ Chí Minh; \\ bvquang09@gmail.com,buivandanh@gmail.com
}

Tóm tắt. Đảm bảo chất lượng mà hoạt động chính là đánh giá chất lượng đã trở thành một phong trào rộng khắp trên toàn thế giới, trong đó có khu vực Đông Nam Á nói chung và Việt Nam nói riêng. Mô hình đánh giá chất lượng đào tạo HEdPERF (Higher Education Performance) được sử dụng ở các nước trên thế giới nhưng vẫn còn mới đối với Việt Nam. Việc sử dụng mô hình này sẽ giúp khẳng định tính hợp lý của các chuẩn mực trong đánh giá chất lượng đào tạo theo tiêu chuẩn quốc tế. Phương pháp nghiên cứu là ngẫu nhiên có phân tổ với số mẫu là 258 sinh viên. Kết quả nghiên cứu cho thấy các yếu tố: Phi học thuật; Học thuật, Chương trình, Đánh giá, Danh tiếng, Tiếp cận, và Nhóm tham gia có mối quan hệ với sự hài lòng của sinh viên đối với chất lượng đào tạo. Từ nghiên cứu, một số đề xuất hàm ý quản trị đối với các trường đại học và các cơ quan quản lý giáo dục liên quan.

Từ khóa. Mô hình HEdPERF, đào tạo, sinh viên, sự hài lòng, giáo dục chất lượng cao

\section{HEDPERF RESEARCH MODEL IN ASSESSING TRAINING QUALITY RESEARCH STUDY: INDUSTRIAL UNIVERSITY OF HO CHI MINH CITY}

\begin{abstract}
Quality assurance whose main activity is to assess the quality has become a mass movement around the world, including Southeast Asia region as well as in general and Vietnam in particular. Assessment model of training quality HEdPERF (Higher Education Performance) used in countries around the world but new to Vietnam. Using this model will help confirm the reasonableness of the criteria in assessing training quality according to international standards. Research methodology is randomized sample with 258 students. The study results showed that the following factors: Nonacademic, academic, program, assessment, reputation, access and group size has relationships between student satisfaction with the quality of education. From the research, some implications are proposed for universities and education authorities concerned.
\end{abstract}

Keywords. HEdPERF model, training, student satisfaction, high-quality education

\section{GIỚI THIỆU}

Mặc dù đã có những nghiên cứu trước đây về chất lượng đào tạo trường đại học ở Việt Nam nhưng nghiên cứu chủ yếu chỉ dừng lại mô hình SERVPERF. Trong nghiên cứu đề tài này, nhóm tác giả đã sử dụng mô hình nghiên cứu mới HEdPERF (Higher Education Performance) vào nghiên cứu chất lượng đào tạo. Đây cũng là một mô hình mới của chất lượng dịch vụ trong ngành giáo dục và được áp dụng ở các nước trên thế giới trong lĩnh vực đào tạo đại học. Để đánh giá chất lượng đào tạo theo mô hình HEdPERF, chúng tôi đã tiến hành nghiên cứu điển hình tại trường Đại học Công nghiệp TP. Hồ Chí Minh nhằm xác định những giải pháp cụ thể. Nội dung nghiên cứu chủ yếu gồm mô hình định lượng liên quan các yếu tố ảnh hưởng sự hài lòng của sinh viên và đề xuất hàm ý quản trị theo mô hình HEdPERF.

\section{TỔNG QUAN NGHIÊN CÚU VÀ KHUNG LÝ THUYẾT}

\subsection{Chất lượng đào tạo tại trường đại học}

Chất lượng đào tạo đại học là một khái niệm quá quen thuộc nhưng được định nghĩa rất khác nhau tùy theo từng thời điểm và giữa những người quan tâm: Sinh viên, giảng viền, người sử dụng lao động, các tổ chức tài trợ và các cơ quan kiểm định; trong nhiều bối cảnh, nó còn phụ thuộc vào tình trạng phát 
triển kinh tế - xã hội của mỗi nước. Ở Việt Nam, khái niệm “chất lượng” và các cách tiếp cận khác nhau về chất lượng được nhiều nhà nghiên cứu giáo dục đề cập trong các ấn phẩm của mình.

Theo tác giả Nguyễn Đức Chính (2002) hiện nay trên thế giới có sáu quan điểm về chất lượng GDĐH nhu sau [8]:

(1) Chất lượng được đánh giá "đầu vào" như một trường ĐH có chất lượng cao nếu tuyển được nhiều SV giỏi, có đội ngũ cán bộ giảng dạy có uy tín, có cơ sở vật chất tốt và trang thiết bị hiện đại..

(2) Chất lượng được đánh giá "đầu ra" như trường $Đ H$ có chất lượng cao nếu đào tạo được nhiều SV tốt nghiệp giỏi, thực hiện được nhiều công trình khoa học có giá trị, nhiều khóa học thu hút người học...

(3) Chất lượng được đánh giá bằng "giá trị gia tăng" như trường $\mathrm{ĐH}$ có chất lượng cao nếu tạo được sự khác biệt lớn trong sự phát triển về trí tuệ và cá nhân SV sau quá trình đào tạo tại trường.

(4) Chất lượng được đánh giá bằng "giá trị học thuật" như trường $\mathrm{ĐH}$ có chất lượng cao nếu có được đội ngũ cán bộ giảng dạy, các nhà khoa học có uy tín lớn.

(5) Chất lượng được đánh giá bằng "văn hoá tổ chức riêng" như trường $Đ H$ có chất lượng cao nếu có được một truyền thống tốt đẹp về hoạt động không ngừng nâng cao chất lượng đào tạo.

(6) Chất lượng được đánh giá bằng "kiểm toán" như trường $\mathrm{DH}$ có chất lượng cao nếu kết quả kiểm toán chất lượng cho thấy nhà trường có thu thập đủ thông tin cần thiết và những người ra các quyết định về có đủ thông tin cần thiết, sự hợp lý và hiệu quả của quá trình thực hiện các quyết định về chất lượng.

Trên cơ sở phân tích sáu quan điểm nêu trên, mỗi quan điểm có những ưu và hạn chế khác nhau nên chất lượng đào tạo dựa trên mỗi quan điểm trên là không phù hợp.

Trong giai đoạn hội nhập quốc tế toàn diện và sâu sắc như hiện nay, chất lượng đào tạo đại học dịch chuyển từ đảm bảo chất lượng tiến dần sang chất lượng thỏa mãn nhu cầu của khách hàng và thông qua khách hàng có sự hỗ trợ của đảm bảo chất lượng.

Cách tiếp cận khái niệm chất lượng thông qua khách hàng làm thay đổi quan điểm về chất lượng đào tạo đại học thay vì như cách tiếp cận truyền thống trước đây. Chất lượng sản phẩm đào tạo của các trường ĐH phải được đánh giá bởi khách hàng và kết quả đánh giá là cơ sở để các trường $Đ H$ xây dựng kế hoạch cải tiến nhằm không ngừng nâng cao chất lượng đào tạo của nhà trường. Do vậy, cần tiếp cận tích hợp để quản lý chất lượng đào tạo, đáp ứng tốt hơn những kỳ vọng mong muốn của sinh viên.

\subsection{Khái niệm về Sự hài lòng của sinh viên}

Theo Kotler và Keller (2006) sự hài lòng là trạng thái của mức độ cảm giác của một người bắt nguồn từ việc so sánh nhận thức về một sản phẩm so với mong đợi của người đó. Sự hài lòng của sinh viên trong trường đại học được Kaldenberg et al. (1998) giải thích theo nhiều cách như đánh giá của người học về chất lượng của các môn học, hoạt động ngoại khóa và các yếu tố liên quan như giảng viên đối xử với sinh viên hoặc những hỗ trợ cần thiết từ trường học. Elliot và Healy (2001) đề xuất sự hài lòng của sinh viên là một thái độ ngắn hạn, xuất phát từ việc đánh giá của các dịch vụ giáo dục nhận được.

\subsection{Những nghiên cứu trước đây về chất lượng đào tạo và sự thoả mãn của sinh viên}

Có một số nghiên cứu được thực hiện trong quá khứ cho thấy chất lượng đào tạo của giáo dục đại học dẫn đến sự hài lòng của sinh viên. Theo Firdaus Abdullah (2005), mặc dù SERVQUAL, SERVPERF được thiết kế như là các công cụ chung dùng để đo lường chất lượng dịch vụ trong đa số ngành công nghiệp nhưng khi áp dụng thường phải sửa đổi thang đo để phù hợp với tình hình cụ thể và thường có những yếu tổ bổ sung. Chính vì vậy, ông đã đề xuất mô hình HEdPERF để đo lường chất lượng trong giáo dục đại học, sau đó, ông tiếp tục thực hiện nghiên cứu nhằm mục đích kiểm tra và so sánh hiệu quả tương đối của ba công cụ đo lường chất lượng dịch vụ được sử dụng trong lĩnh vực giáo dục đại học, cao đẳng là HEdPERF, SERVPERF và kết hợp HEdPERF - SERVPERF. Kết quả đã chỉ ra rằng, các đo lường về chất lượng dịch vụ của HEdPERF đáng tin cậy hơn, tiêu chuẩn lớn hơn, các khái niệm có hiệu lực hơn, giải thích phương sai lớn hơn. Mô hình HEdPERF với 5 thành phần là Các khía cạnh phi học thuật, Các khía cạnh học thuật, Co sở vật chất, Chuoong trình đào tạo, Sự tiếp nhận.

Để chứng minh tính hiệu quả của mô hình HEdPERF, Qi Huang (2009) sử dụng mô hình HEdPERF để nghiên cứu về sự hài lòng của sinh viên trường đại học Hạ Môn - Trung Quốc. Kết quả chỉ ra rằng, mối quan hệ giữa các khía cạnh phi học thuật với sự hài lòng của sinh viên khá mạnh mẽ. Còn đối với 
khía cạnh học thuật, sự hài lòng sẽ tăng lên khi trường đại học có sự cải tiến về chất lượng giảng dạy. Sinh viên khá hài lòng khi giảng viên áp dụng những phương pháp giảng dạy phù hợp. Còn đối với các vấn đề liên quan đến chương trình học, có mối liên hệ vừa phải với sự hài lòng. Điều này có nghĩa là khi trường đại học nỗ lực trong việc cải tiến chương trình học, sinh viên sẽ hài lòng hơn. Sự tiếp cận là một trong những thành phần quan trọng nhất của chất lượng dịch vụ trong giáo dục đại học.

Một nghiên cứu về sự hài lòng của sinh viên khoa quốc tế và châu Âu của 2 tác giả G.V. Diamantis và V.K. Benos, trường đại học Piraeus, Hy Lạp thực hiện năm 2007 cho rằng, sự hài lòng của sinh viên về khóa học tùy thuộc vào nhiểu yếu tố như chương trình đào tạo, các môn học, đội ngũ giảng viên, giáo trình, kinh nghiệm xã hội, kinh nghiệm trí tuệ của cơ sở giáo dục. Theo Brochado (2009), mô hình HEdPERF phân biệt các khía cạnh phi học thuật, khía cạnh học thuật, các vấn đề chương trình, truy cập, và uy tín trong dịch vụ giáo dục cao hơn, nó có mối tương quan cao với sự hài lòng tổng thể của sinh viên.

Ở các nước Châu Âu, việc nghiên cứu chất lượng đào tạo trong thời gian gần đây đã áp dụng mô hình mới HEdPERF đúng với lĩnh vực giáo dục nên các yếu tố đo lường chính xác hơn. Do vậy, việc xác định công cụ đo lường chất lượng phù hợp hơn trong nghiên cứu là rất cần thiết nhằm tìm ra những nhân tố ảnh hưởng đến sự hài lòng của sinh viên và là cơ sở đề xuất giải pháp hiệu quả đối với hoạt động đào tạo.

\subsection{Mô hình lý thuyết trong việc nghiên cứu chất lượng đào tạo đại học}

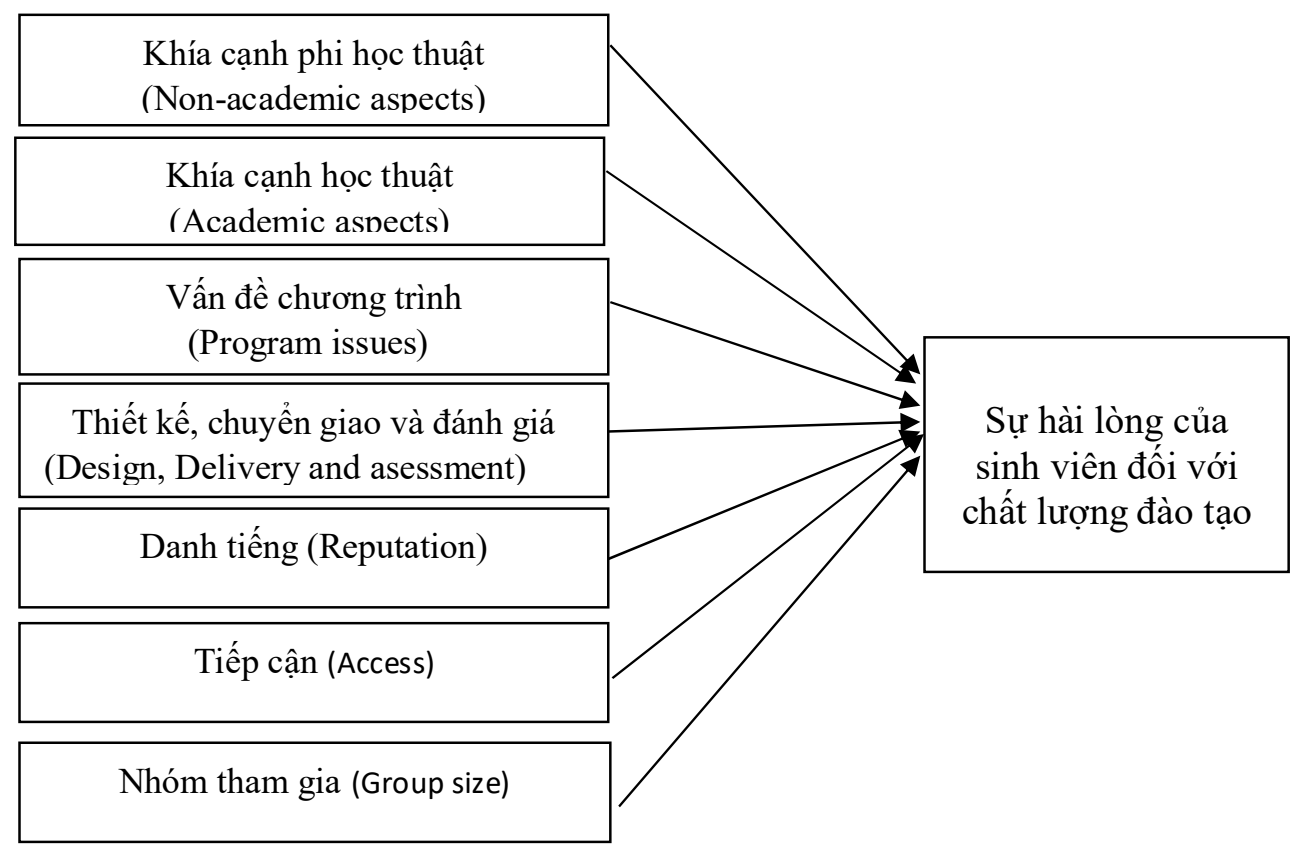

Hình 1. Mô hình HEdPERF lý thuyết về chất lượng đào tạo tại trường đại học

Mô hình chất lượng dịch vụ trong trường đại học HEdPERF (Higher Education Performance) không những đã được chấp nhận bởi các nhà nghiên cứu mà còn là một công cụ hiệu quả để đo lường chất lượng dịch vụ trong giáo dục đại học. Từ những phân tích về các biến HEdPERF của Firdaus, A. (2005), nghiên cứu của Afjal et al. (2009) về chất lượng dịch vụ đại học, mối quan hệ giữa chất lượng đào tạo và sự hài lòng của sinh viên, mô hình cơ bản đánh giá chất lượng đào tạo đại học[5] (Hình 1)

\subsection{Mô hình nghiên cứu HEdPERF thực tế}

Nhóm tác giả đã sử dụng mô hình nghiên cứu HEdPERF vào dịch vụ đào tạo tại Việt Nam nên những đặc điểm của đại học Việt Nam nói chung và Đại học Công Nghiệp TP.HCM (ĐHCN TP.HCM) có khác so với các trường đại học có tên tuổi ở nước ngoài. Chẳng hạn, trong quá trình nghiên cứu định tính như khảo sát ý kiến sinh viên, tham khảo góp ý của giảng viên trường ĐHCN.TP HCM và các trường 
khác, nhóm tác giả đã điều chỉnh các yếu tố nghiên cứu phù hợp tình hình trường đại học Việt Nam và trường ĐHCN TP.HCM như sau: Biến Thiết kế, Chuyển giao và Đánh giá được gom lại thành biến Đánh giá, riêng thành phần trong Thiết kế và Chuyển giao được bổ sung vào biến Chương trình và Học Thuật.

\section{Các giả thuyết nghiên cứu}

Giả thuyết $\mathrm{H}_{01}$ : Yếu tố phi học thuật có tương quan dương với sự hài lòng của sinh viên.

Giả thuyết H02: Yếu tố học thuật có tương quan dương với sự hài lòng của sinh viên.

Giả thuyết H03: Yếu tố chương trình đào tạo có tương quan dương với sự hài lòng của sinh viên.

Giả thuyết H04: Yếu tố đánh giá có tương quan dương với sự hài lòng của sinh viên.

Giả thuyết H05: Yếu tố danh tiếng có tương quan dương với sự hài lòng của sinh viên.

Giả thuyết H06: Yếu tố tiếp cận có tương quan dương với sự hài lòng của sinh viên.

Giả thuyết H07: Yếu tố nhóm tham gia có tương quan dương với sự hài lòng của sinh viên.

Như vậy mô hình HEdPERF áp dụng trong nghiên cứu chất lượng đào tạo trường ĐHCN.HCM được trình bày lại với 7 yếu tố như sau (Hình 2)

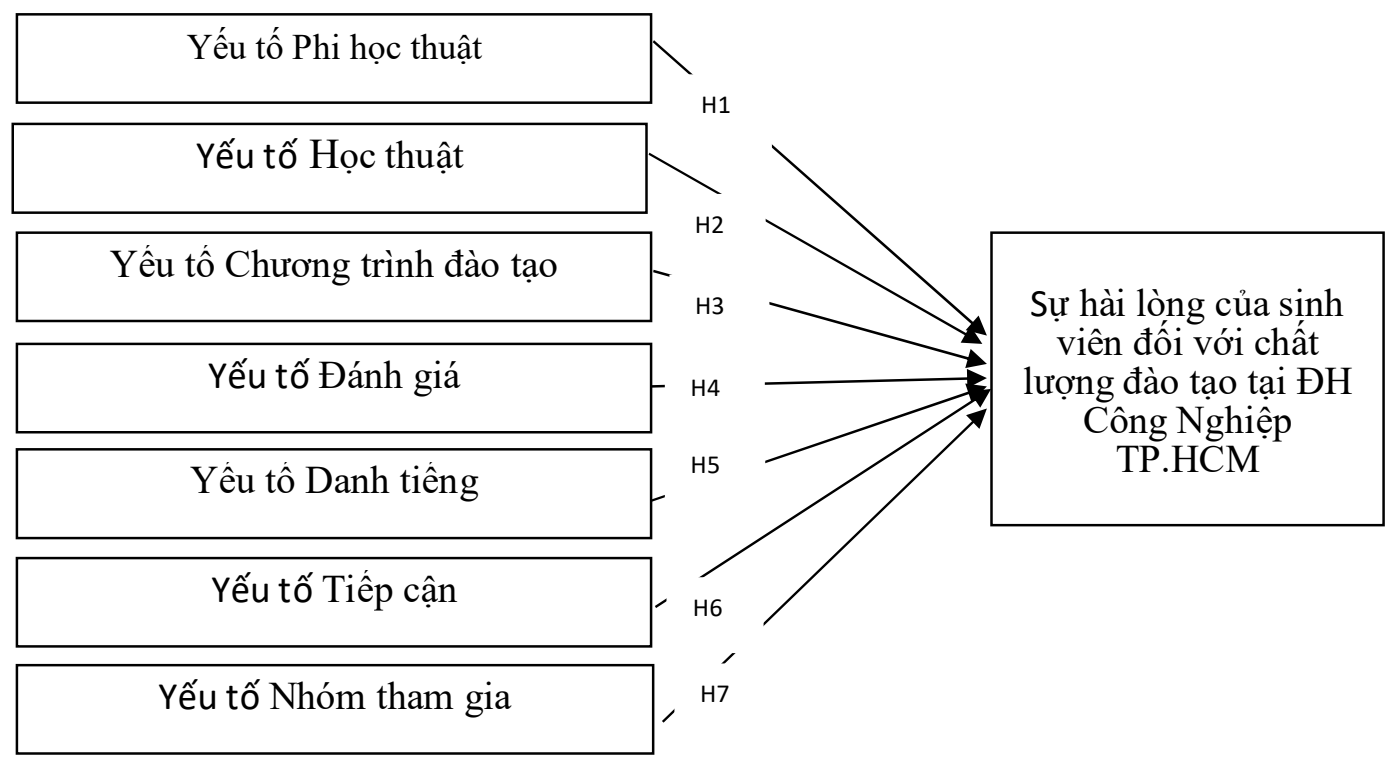

Hình 2. Mô hình HEdPERF thực tế về chất lượng đào tạo tại trường đại học

Trong nghiên cứu này, các biến độc lập là 7 biến chất lượng dịch vụ: Yếu tố Phi học thuật, yếu tố Học thuật, Chương trình, Đánh giá, Danh tiếng, Tiếp cận và Kích thước nhóm. Biến phụ thuộc là Sự hài lòng của sinh viên đối với chất lượng đào tạo.

\section{PHƯƠNG PHÁP NGHIÊN CÚU}

\subsection{Nghiên cứu định tính}

Từ thang đo HEdPERF, nghiên cứu định tính được sử dụng kỹ thuật thảo luận tay đôi kết hợp thảo luận nhóm qua dàn bài được chuẩn bị sẵn, kết hợp với cơ sở lý thuyết để xây dựng và điều chỉnh. Thang đo Litkert 5 điểm được sử dụng với 1 là hoàn toàn không đồng ý và 5 là hoàn toàn đồng ý. Trên cơ sở mô hình HEdPERF, thang đo chất lượng đào tạo được xây dựng gồm 08 thành phần, 39 biến quan sát, trong đó thành phần (1) Khía cạnh phi học thuật: 05 biến quan sát; (2) Khía cạnh học thuật: 8 biến quan sát; (3) Vấn đề chương trình: 07 biến quan sát; (4) Đánh giá: 6 biến quan sát; (5) Danh tiếng: 04 biến quan sát; (6) Tiếp cận: 03 biến quan sát; (7) Nhóm tham gia: 03 biến quan sát, (8) Đánh giá chung: 03 biến quan sát như sau (Bảng 1):

Bảng 1. Thang đo các thành phần chất lượng đào tạo 


\begin{tabular}{|c|c|}
\hline Ký hiệu & Câu hỏi các biến khảo sát \\
\hline P-Hocthuat & Phi học thuật \\
\hline P Hocthuat $_{1}$ & Khi sinh viên gặp trở ngại, cán bộ quản lý khoa giải quyết thỏa đáng \\
\hline $\mathrm{P}$ Hocthuat 2 & Nhân viên hành chánh lưu trũ hò̀ so chính xác và dễ sủ dụng. \\
\hline P_Hocthuat 3 : & Nhân viên hành chánh luôn giũ lòi húa trong quá trình phục vụ SV. \\
\hline $\bar{P}$ Hocthuat $_{4}$ & Nhân viên hành chính có thái độ làm việc thân thiện đối với sinh viên. \\
\hline $\mathrm{P}$ Hocthuat 5 & Nhân viên hành chính có kiến thức tốt về các qui trình phục vu SV. \\
\hline Hocthuat & Học thuật \\
\hline Hocthuat $_{1}$ & Giảng viên sẵn sàng chia sẻ kinh nghiệm và kiến thức với sinh viên. \\
\hline Hocthuat $_{2}$ & $\begin{array}{l}\text { Giảng viên hướng dẫn có sư quan tâm chân thành trong việc giải } \\
\text { quyết vấn đề của sinh viên. }\end{array}$ \\
\hline Hocthuat $_{3}$ & Giảng viên tuoong tác tốt trong lóp học. \\
\hline Hocthuat $_{4}$ & Giảng viên có bằng cấp cao trong lĩnh vưc của mình. \\
\hline Hocthuat $_{5}$ & Giảng viên đảm bảo giờ lên lớp và kế hoạch giảng dạy. \\
\hline Hocthuat $_{6}$ & Giảng viên có kiến thức sâu rộng về chuyên môn. \\
\hline Hocthuat $_{7}$ & Phuơng pháp giảng dạy của giảng viên phù hợp. \\
\hline Hocthuat 8 & Giảng viên thuờng xuyên sủ dụng công nghệ thông tin hỗ trợ giảng dạy. \\
\hline Ký hiệu & Chương trình đào tạo \\
\hline Chuongtrinh $_{1}$ & Truờng có nhiều chương trình đào tạo đa dạng. \\
\hline Chuongtrinh $_{2}$ & Khối lương kiến thức chuơng trình đào tạo phù hợp. \\
\hline Chuongtrinh $_{3}$ & Khóa hoc được thiết kế đáp úng được mong đợi của sinh viên. \\
\hline Chuongtrinh $_{4}$ & Tỷ lẹ giũ̃a lý thuyết và thưc hành hợp lý. \\
\hline Chuongtrinh $_{5}$ & Giáo trình mối môn được cung cấp đầy đủ đa dạng. \\
\hline Chuongtrinh $_{6}$ & Giáo trình được biên soạn rõ ràng, chính xác. \\
\hline Chuongtrinh $_{7}$ & Sách báo, tài liệu thu viện thuờng xuyên được cập nhật \\
\hline Ký hiệu & Đánh giá \\
\hline Danhgia $_{1}$ & Việc đánh giá và chấm điểm bởi giảng viên là công bằng. \\
\hline Danhgia $_{2}$ & Đánh giá kết quả học tập bởi giảng viên là chính xác. \\
\hline Danhgia $_{3}$ & Giảng viên sư dụng nhiều hình thức kiểm tra, đánh giá môn học. \\
\hline Danhgia $_{4}$ & Công tác tổ chức thi củ nghiêm túc, chặt chẽ. \\
\hline Danhgia $_{5}$ & Sinh viên được thông báo đầy đủ kế hoạch giảng dạy. \\
\hline Danhgia $_{6}$ & Sinh viên được thông báo đầy đủ tiêu chi đánh giá kết quả học tập. \\
\hline Ký hiệu & Danh tiếng \\
\hline Danhtieng $_{1}$ & Truờng có một hình ảnh chuyên nghiệp. \\
\hline Danhtieng $_{2}$ & Chương trình đào tạo của trường có uy tín. \\
\hline Danhtieng $_{3}$ & Sinh viên tốt nghiệp của truờng có thể dễ dàng duợc tuyển dụng. \\
\hline Danhtieng $_{4}$ & Ngành đào tạo đáp úng nhu cầu nhân lực của xã họi. \\
\hline Ký hiệu & Tiếp cận \\
\hline Tiepcan $_{1}$ & Nhân viên hành chánh có thể dễ dàng hỗ trợ cho sinh viên. \\
\hline Tiepcan $_{2}$ & Đội ngũ giảng viên phân bổ đủ thời gian để sinh viên tham khảo ý kiến. \\
\hline Tiepcan $_{3}$ & Nhân viên hành chánh tạo điều kiện cho sinh viên có thể dễ dàng liên lạc. \\
\hline Ký hiệu & Nhóm tham gia \\
\hline NhomTG $_{1}$ & Số luợng sinh viên trong một lớp hơp lý (40-60 sinh viên). \\
\hline NhomTG $_{2}$ : & Quy mô lớp học phù hợp giúp các sinh viên turơng tác nhiều hơn. \\
\hline \multirow[t]{2}{*}{ NhomTG $_{3}$} & Lớp học vì̀a phải giúp sinh viên hiểu rõ hơn. \\
\hline & Hài lòng \\
\hline Hailong $_{1}$ & Nếu được chọn lại bạn sẽ lại chọn truờng mình đang hoc. \\
\hline Hailong 2 & Bạn hài lòng về chất luợng đào tạo \\
\hline Hailong $_{3}$ & Bạn sẽ khuyên người khác chọn trưòng ĐH CN TP.HCM \\
\hline
\end{tabular}




\subsection{Nghiên cứu định lượng}

Mẫu được chọn theo phương pháp ngẫu nhiên có phân tổ theo ngành, năm học, sinh viên đang học và sinh viên vừa học vừa làm nhằm đảm bảo tính đại diện trong việc đánh giá chất lượng đào tạo của trường. Mẫu nghiên cứu giới hạn là sinh viên Trường $\mathrm{ĐHCN} \mathrm{TPHCM} \mathrm{với} 4$ ngành khối kinh tế đại diện gồm Quản trị Kinh doanh, Kế toán Kiểm toán, Tài chính Ngân hàng và Thương mại Du lịch. Về đặc điểm năm học, đối tượng phỏng vấn là sinh viên đại học từ năm 1 (chiếm tỷ lệ $23,9 \%$ ), sinh viên năm 2 $(24,8 \%)$, sinh viên năm $3(27,4 \%)$, sinh viên năm $4(23,8 \%)$. Về đặc điểm ngành học, sinh viên ngành học Quản trị Kinh doanh (chiếm tỷ lệ cao nhất với $27,2 \%$ ), ngành Kế toán-Kiểm toán $(25,1 \%$ ), ngành Tài chính Ngân Hàng $(24,5 \%)$ và ngành Thương Mại-Du lịch(23,2\%).

Tổng số mẫu được khảo sát là 280 , thu về 264 , số mẫu không hợp lệ là 6 , số mẫu hợp lệ là 258 . Thời gian thực hiện cuộc khảo sát từ 3/09/2016 đến 28/10/2016.

\section{Kết quả và thảo luận}

\section{1. Đánh giá thang đo}

Kết quả kiểm định độ tin cậy Cronbach Alpha các thang đo cho thấy tất cả đề từ 0,69 trở lên (Bảng 2) và các hệ số tương quan biến tổng của các thang đo đều cao hơn mức cho phép (lớn hơn 0.3 ) nên tất cả các thang đo đều đạt yếu cầu.

Bảng 2. Tóm tắt kết quả kiểm định Cronbach Alpha các thang đo

\begin{tabular}{|l|l|c|c|c|c|}
\hline \multicolumn{1}{|c|}{ Mã thang đo } & \multicolumn{1}{|c|}{ Các thang đo } & $\begin{array}{c}\text { Số biến } \\
\text { quan sát }\end{array}$ & $\begin{array}{c}\text { Độ tin cậy } \\
\text { Cronbach } \\
\text { Alpha }\end{array}$ & $\begin{array}{c}\text { Phương sai } \\
\text { trích } \\
(\%)\end{array}$ & $\begin{array}{c}\text { Tương quan } \\
\text { biến- tông }\end{array}$ \\
\hline P_Hocthuat & Phi học thuật & 258 & 0,7971 & 0.97 & $0,51-0,63$ \\
\hline Hocthuat & Học thuật & 258 & 0,6837 & 0.84 & $0,22-0,56$ \\
\hline Chuong trinh & Chương trình & 258 & 0,7588 & 0.89 & $0,31-0,57$ \\
\hline Đanh gia & Đánh giá & 258 & 0,7071 & 0.93 & $0,21-0,52$ \\
\hline Danhtieng & Danh tiếng & 258 & 0,8413 & 1.05 & $0,53-0,78$ \\
\hline Tiepcan & Tiếp cận & 258 & 0,7112 & 0.89 & $0,53-0,54$ \\
\hline NhomTG & Nhóm tham gia & 258 & 0,7253 & 9,92 & $0,54-0,58$ \\
\hline Hailong & Hài lòng & 258 & 07580 & 0,97 & $0,54-0.63$ \\
\hline
\end{tabular}

Nguồn: Tác giả trực tiếp nghiên cứu

\subsection{Phân tích nhân tố khám phá (EFA)}

Kết quả phân tích nhân tố khám phá $(\mathrm{EFA})$ lần 1 cho thấy: Giữa các biến trong tổng thể có mối liên quan với nhau (sig. $=0,000$ ) và hệ số $\mathrm{KMO}=0,760$, chứng tỏ sự thích hợp của $\mathrm{EFA}$. Giá trị Eigenvalue $=1,095 ; 36$ biến quan sát được nhóm lại thành 10 nhân tố. Tổng phương sai trích là 82,059 chứng tỏ 10 nhân tố này giải thích được $82,049 \%$ biến thiên của các biến quan sát.

Ma trận các nhân tố đã xoay trong kết quả EFA lần 1 có một số biến bị loại là: Tiepcan 1, $\mathrm{P}_{\text {_Hocthuat }}$, Chuongtrinh ${ }_{1}$, Hocthuat ${ }_{1}$. Số biến quan sát còn lại là 32 được phân tích nhân tố khám phá EFA lần 2.(Bảng 3)

Kết quả phân tích EFA lần 2: Giữa các biến trong tổng thể có mối liên quan với nhau ( $(\operatorname{sig} .=0,000)$ và hệ số $\mathrm{KMO}=0,878$ chứng tỏ sự thích hợp của EFA. Giá trị Eigenvalue $=1,045,32$ biến quan sát được nhóm lại thành 8 nhân tố. Tổng phương sai trích là 72,356 chứng tỏ 8 nhân tố này giải thích được 72,356 $\%$ biến thiên của các biến quan sát.

Ma trận các nhân tố đã xoay trong kết quả EFA lần 2 có trọng số lớn hơn mức tối thiểu và được chia thành 8 nhân tố. 
MÔ HİNH NGHIÊN CỨU HEDPERF TRONG ĐÁNH GIÁ CHÂTT LƯợNG ĐÀO TẠO TİNH HUỐNG NGHIÊN CÚU: TRƯỜNG ĐẠI HỌC CÔNG NGHIỆP TP. HỔ CHÍ MINH

Bảng 3. Ma trận các nhân tố đã xoay trong kết quả EFA lần 2

\begin{tabular}{|c|c|c|c|c|c|c|c|c|}
\hline & 1 & 2 & 3 & 4 & 5 & 6 & 7 & 8 \\
\hline P_Hocthuat5 & .933 & & & & & & & \\
\hline Tiepcan3 & .927 & & & & & & & \\
\hline Hocthuat2 & .782 & & & & & & & \\
\hline P_Hocthuat4 & .719 & & & & & & & \\
\hline Tiepcan2 & .645 & & & & & & & \\
\hline P_Hocthuat2 & .588 & & & & & & & \\
\hline P_Hocthuat3 & .512 & & & & & & & \\
\hline Danhtieng3 & & .946 & & & & & & \\
\hline Chuongtrinh3 & & .823 & & & & & & \\
\hline Danhtieng2 & & .710 & & & & & & \\
\hline Danhtieng4 & & .650 & & & & & & \\
\hline Danhtieng1 & & .629 & & & & & & \\
\hline Chuongtrinh5 & & & .834 & & & & & \\
\hline Chuongtrinh6 & & & .753 & & & & & \\
\hline Chuongtrinh4 & & & .682 & & & & & \\
\hline Chuongtrinh2 & & & .631 & & & & & \\
\hline Chuongtrinh7 & & & .572 & & & & & \\
\hline Hocthuat5 & & & & .762 & & & & \\
\hline Hocthuat4 & & & & .666 & & & & \\
\hline Hocthuat8 & & & & .585 & & & & \\
\hline Hocthuat7 & & & & .521 & & & & \\
\hline Hocthuat6 & & & & .426 & & & & \\
\hline NhomTG2 & & & & & .875 & & & \\
\hline NhomTG1 & & & & & .648 & & & \\
\hline NhomTG3 & & & & & .544 & & & \\
\hline Danhgia2 & & & & & & .862 & & \\
\hline Danhgial & & & & & & .764 & & \\
\hline Hocthuat3 & & & & & & .75 & & \\
\hline Danhgia5 & & & & & & & .916 & \\
\hline Danhgia6 & & & & & & & .818 & \\
\hline Danhgia4 & & & & & & & & .856 \\
\hline Danhgia3 & & & & & & & & .656 \\
\hline Eigenvalue & 9.115 & 4.358 & 2.108 & 1.861 & 1.776 & 1.272 & 1.215 & 1.045 \\
\hline Phương sai trích & 37.630 & 44.218 & 52.264 & 57.302 & 61.586 & 65.583 & 67.131 & 72.356 \\
\hline
\end{tabular}

Nguồn: Tác giả trực tiếp nghiên cứu 


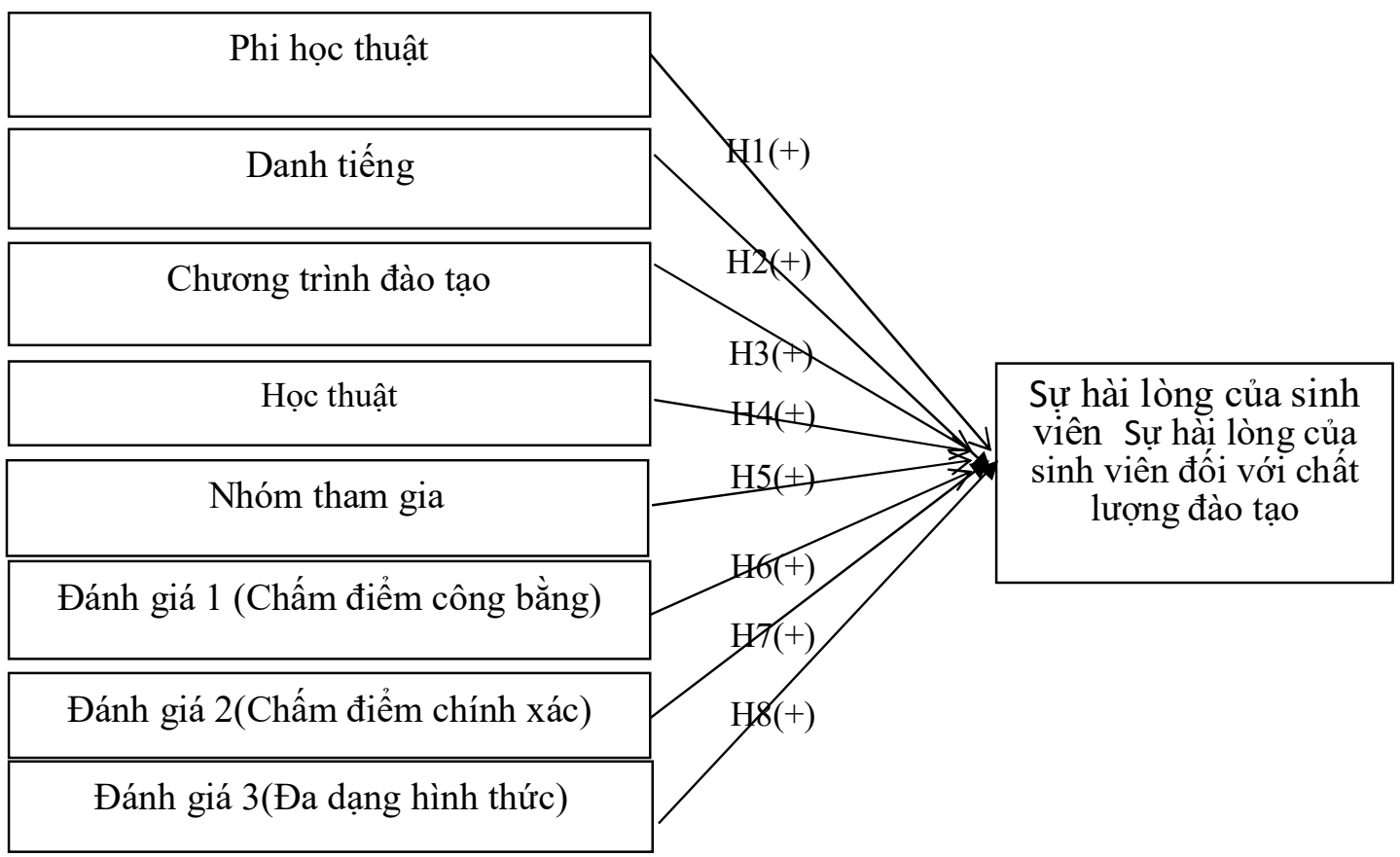

Hình 3. Mô hình nghiên cứu điều chỉnh từ kết quả phân tích EFA.

Như vậy, mô hình nghiên cứu điều chỉnh từ kết quả phân tích nhân tố khám phá EFA lần 2 được đưa ra bao gồm 8 biến độc lập (1)Phi học thuật, (2)Danh tiếng (3)Chương trình đào tạo, (4)Học thuật, (5)Nhóm tham gia, (6)Đánh giá 1, (7)Đánh giá 2 và (8)Đánh giá 3.

\subsection{Phương trình hồi quy tuyến tính}

Bảng 4. Các thông số của từng biến trong phương trình hồi quy

\begin{tabular}{|c|c|c|c|c|c|c|c|c|}
\hline & \multirow[t]{2}{*}{ Mô hình } & \multicolumn{2}{|c|}{$\begin{array}{c}\text { Hệ số chưa chuẩn } \\
\text { hóa }\end{array}$} & \multirow{2}{*}{$\begin{array}{c}\begin{array}{c}\text { Hệ số } \\
\text { chuấn hóa }\end{array} \\
\text { Beta }\end{array}$} & \multirow[t]{2}{*}{$\mathrm{T}$} & \multirow[t]{2}{*}{$\begin{array}{l}\text { Mức ý } \\
\text { nghĩa } \\
\text { (Sig.). }\end{array}$} & \multicolumn{2}{|c|}{ Chỉ số đa cộng tuyến } \\
\hline & & B & $\begin{array}{l}\text { Sai số } \\
\text { chuẩn }\end{array}$ & & & & $\begin{array}{l}\text { Chỉ số mức } \\
\text { chịu đựng }\end{array}$ & $\begin{array}{l}\text { Hệ số phóng } \\
\text { đại(VIF) }\end{array}$ \\
\hline 1 & (Hằng số) & .566 & .291 & & 1.146 & .010 & & \\
\hline & $\mathrm{X} 1$ & .328 & .057 & .303 & 5.732 & .000 & .714 & 1.351 \\
\hline & $\mathrm{X} 2$ & .195 & .068 & .169 & 2.497 & .012 & .445 & 2.783 \\
\hline & $\mathrm{X} 3$ & .314 & .081 & .256 & 3.755 & .000 & .354 & 2.265 \\
\hline & $\mathrm{X} 4$ & .121 & .092 & .112 & 1.859 & .011 & .436 & 1.765 \\
\hline & $\mathrm{X} 5$ & .139 & .052 & .129 & 2.629 & .032 & .782 & 1.484 \\
\hline & $\mathrm{X} 6$ & .286 & .059 & .229 & 3.080 & .013 & .756 & 1.528 \\
\hline & $\mathrm{X} 7$ & .057 & .049 & .052 & 1.129 & .374 & .861 & 1.386 \\
\hline & $\mathrm{X} 8$ & .073 & .057 & .061 & 1.390 & .321 & .953 & 1.183 \\
\hline
\end{tabular}

a Dependent Variable:

Nguồn: Tác giả trực tiếp nghiên cứu

Kết quả hồi quy cho thấy trị số thống kê $\mathrm{F}=17,045$, tại mức ý nghĩa Sig $=0.000$; đại lượng thống kê Durbin-Watson $=1.892(1<1.892<3)$ cho thấy không có sự tương quan giữa các phần dư. Hệ số xác định $\mathrm{R}^{2}$ điều chỉnh (Adjusted $\mathrm{R}$-quare) là 0,654 . Tiêu chuẩn chấp nhận các biến đều có giá trị Tolerance $>0,0001$. Hệ số phóng đại phương sai VIF của từng nhân tố có giá trị nhỏ hơn 10 , chứng tỏ mô hình hồi quy không vi phạm hiện tượng Đa cộng tuyến. Biểu đồ tần số của phần dư chuẩn hóa cho thấy phần phối 
của phần dư xấp xỉ chuẩn (Trung bình=0 và độ lệch chuẩn Std.Dev.=0.99). Như vậy, mô hình hồi quy tuyến tính bội đưa ra là phù hợp với mô hình và dữ liệu nghiên cứu.

Kết quả phân tích hồi quy được trình bày trong Bảng 4, cho thấy: Có 2 nhân tố: nhân tố X7 (Đánh giá 2) và X8(Đánh giá 3 ) có mức ý nghĩa sig. $>0.05$ nên không chấp nhận; Có 6 nhân tố: X1(Phi học thuật), $\mathrm{X}$ 2(Danh tiếng), X3(Chương trình đào tạo), X4(Học thuật), X5(Nhóm tham gia) và X6(Đánh giá 1 ) có mức ý nghĩa sig. $<0.05$, và đều có tác động dương (hệ số Beta dương) đến $Y$ (sự hài lòng của sinh viên) ở tất cả các biến nên được chấp nhận trong phương trình hồi quy.

Từ phân tích trên, phương trình hồi quy có dạng như sau: $\mathrm{Y}($ Sự hài lòng của $\mathrm{SV})=0.566+0,303 \mathrm{X} 1$ (Phi học thuật $)+0,256 \mathrm{X} 3$ (Chương trình đào tạo) $+0,229 \mathrm{X} 6$ (Đánh giá 1) + 0,169 X2 (Danh tiếng) + 0,129 X5 (Nhóm tham gia) 0,112 X4 (Học thuật)

\section{Kiểm định các giả thuyết của mô hình nghiên cúu}

Ta thấy có 8 giả thuyết cần kiểm định là $\mathrm{H} 1$ đến $\mathrm{H} 8$. Qua những kết quả phân tích ở trên, dựa vào giá trị sig. trong phân tích hồi quy đa biến, nhóm tác giả nhận thấy 6 giả thuyết đưa ra là $\mathrm{H} 1, \mathrm{H} 2, \mathrm{H} 3, \mathrm{H} 4, \mathrm{H} 5$, H6 đều được chấp nhận do các nhân tố có tác động dương (hệ số Beta dương) đến sự hài lòng sinh viên (Hailong) với mức ý nghĩa Sig. $<0.05$.

\section{KẾT LUẬn VÀ HÀM Ý QUẢN TRI}

Trong mô hình hồi quy, nghiên cứu đã xác định được mức độ quan trọng của các yếu tố tác động trực tiếp đến Sự hài lòng của sinh viên. Xét hệ số Beta chuẩn hóa, ta thấy rằng: nhân tố Phi học thuật có tác động mạnh nhất đến sự hài lòng của $\sinh$ viên $(\beta=0.303)$; nhân tố tác động mạnh thứ 2 là Chương trình đào tạo $(\beta=0.256)$; nhân tố tác động mạnh thứ 3 là Đánh giá $1(\beta=0.229)$; nhân tố tác động mạnh thứ 4 là Danh tiếng $(\beta=0.169)$; nhân tố tác động mạnh thứ 5 là Nhóm tham gia $(\beta=0.129)$; và nhân tố tác động thấp nhất là Học thuật $(\beta=0.112)$.

Để nâng cao sự hài lòng của sinh viên đối với chất lượng đào tạo, tác giả đề xuất một số hàm ý quản trị đối với trường ĐHCN TP.HCM như sau:

\section{Về yếu tố Phi học thuật}

Cần lập kế hoạch và đặt ra chỉ tiêu về chất lượng phục vụ, hỗ trợ sinh viên đối với cán bộ, nhân viên và có chính sách đối với những cải tiến được áp dụng liên quan quy trình hỗ trợ và phục vụ sinh viên. Để hoàn thiện quy trình đào tạo, việc học hỏi các mô hình quản lý ở các trường đại học trong và ngoài nước, ứng dụng mạnh mẽ công nghệ thông tin, nâng cấp trang thiết bị, qua đó tăng cường kiến thức, kênh thông tin cho cán bộ quản lý, giảng viên, nhân viên hành chánh, tạo điêu kiện hỗ trợ và phục vụ sinh viên kịp thời.

\section{Về yếu tố chương trình đào tạo}

Cần đổi mới nội dung chương trình đào tạo theo hướng: chuẩn hoá - hiện đại hóa phù hợp với các trường trong khu vực và nhu cầu doanh nghiệp; nâng cấp giáo trình và tài liệu tham khảo theo hướng tiếp cận thực tiễn và tài liệu tiên tiến nước ngoài; cân đối giữa tỷ lệ lý thuyết và thực hành của từng ngành, từng môn học phù hợp yêu cầu người học và đáp ứng thị trường lao động. Hình thành các trung tâm thuộc Khoa nhằm phục vụ đào tạo và liên kết chặt chẽ với doanh nghiệp, qua đó, đẩy mạnh đào tạo lý thuyết kết hợp ứng dụng thực tế, xây dựng mối quan hệ chặt chẽ với các doanh nghiệp, tạo điều kiện sinh viên tham gia học tập, tham quan, tiếp xúc với môi trường thực tế.

\section{Về yếu tố đánh giá}

Trường cần áp dụng đánh giá theo tiến trình, giảng viên có thể kiểm tra, theo dõi kết quả học tập của sinh viên trong suốt quá trình học tập, qua đó biết chính xác năng lực của sinh viên. Cần xây dựng hệ thống đánh giá thông qua một đơn vị chuyên môn trong nhà trường đảm trách công việc thu thập ý kiến sinh viên, kiểm tra chất lượng giảng dạy cũng như giám sát hoạt động đánh giá và tương tác của từng giảng viên với sinh viên.

\section{Về yếu tố danh tiếng}


Để xây dựng danh tiếng về chất lượng đào tạo, đảm bảo hài lòng của sinh viên, Nhà trường cần xây dựng và quản lý chất lượng đào tạo với người học là trung tâm và các Phòng ban, các Khoa,.. cùng phối hợp nhịp nhàng hướng vào phục vụ sinh viên. Để phục vụ tốt sinh viên, định kỳ Nhà trường lấy ý kiến các lớp trưởng, nhân viên hành chánh, giảng viên, cán bộ quản lý để tìm hiểu kỳ vọng và thiết kế quy trình cũng như chính sách nhằm mạnh dạn thay đổi, điều chỉnh những yếu tố không phủ hợp. Để đảm bảo danh tiếng chất lượng đào tạo thì Nhà trường cũng cần đo lường thành công của sinh viên đầu ra, những người xin việc hoặc đang làm tại doanh nghiệp sau khi tốt nghiệp. Mô hình này cần được thực hiện và cải tiển liên tục tất cả các khâu dựa trên nhu cầu sinh viên và nhân lực xã hội.

\section{Về nhóm tham gia}

Phòng học cần được đầu tư bảo đảm độ thông thoáng và số lượng chổ ngồi hợp lý; thiết bị máy chiếu và micro phục vụ giảng dạy phải chuyên nghiệp. Nhà trường cần thường xuyên kiểm tra và nâng cấp phòng học và sắp xếp lớp với số lượng sinh viên hợp lý từ $40-60$ sinh viên.

\section{Về yếu tố Học thuật}

Cần nâng cao chất lượng đội ngũ giảng viên bằng cách tạo điều kiện cho giảng viên cơ hội học tập; đẩy mạnh việc tạo nguồn và tuyển chọn giảng viên đảm bảo số lượng và chất lượng ổn định lâu dài; giảm bớt và chuẩn hóa khối lượng giảng dạy theo quy định chung của Bộ; tăng thời gian nghiên cứu; điều chỉnh lại chế độ phụ cấp để giảng viên không làm thêm ngoài trường; tập trung nâng cao trình độ chuyên môn và phương pháp giảng dạy. Chế độ khen thưởng và thăng tiến cũng cần thay đổi để lương và các khoản thưởng được tính dựa trên kết quả giảng dạy, công trình nghiên cứu và hoạt động khác ngoài giảng dạy.

So với những nghiên cứu trước đây liên quan mô hình nghiên cứu SERVPERF, mô hình nghiên cứu HEdPERF có những ưu điểm hơn như: Sự hài lòng của sinh viên tăng lên càng cao liên quan yếu tố phi học thuộc, chương trình, cách đánh giá (Liên quan chuẩn đầu ra), danh tiếng, nhóm tham gia. Những yếu tố khác như Học thuật được xem như là yếu tố cần phải có liên quan đến hài lòng của sinh viên nên mức tác động không cao. Kết quả nghiên cứu của mô hình này cũng phản ảnh sự hài lòng của sinh viên đối với đào tạo phù hợp với xu hướng hiện đại.

Những hạn chế của nghiên cứu: Trong nghiên cứu liên quan chất lượng dịch vụ đại học, mô hình nghiên cứu HEdPERF có những thay đổi về các thành phần và biến quan sát đối với trường Đại học ở Châu Âu và khu vực ASEAN. Riêng ở Việt Nam, tác giả sử dụng mô hình nghiên cứu HEdPERF vào dịch vụ đào tạo tại ĐH trong nước nên những đặc điểm của Đại học Việt Nam nói chung và ĐH Công Nghiệp TP.HCM có khác so với các trường đại học có tên tuổi ở nước ngoài như: (1) Hoạt động hỗ trợ sinh viên liên quan thủ tục hành chính ở trường đại học nước ngoài qua nhiều kênh hơn so với trường ĐHCNTP TP HCM; (2) Chương trình đào tạo nước ngoài được thiết kế, thay đổi chủ động do trường quyết định nhưng ở Việt Nam, chương trình khung của từng trường bị ảnh hưởng bởi chương trình khung của Bộ Giáo dục và Đào tạo nên thành phần "Thiết kế, chuyển giao và Đánh giá" trong mô hình phải điều chỉnh lại, hoặc chuyển các biến quan sát sang thành phần khác trong mô hình cho phù hợp; (3)Cách đánh giá sinh viên của trường đại học nước ngoài với nhiều khía cạnh đa dạng hơn do thuận lợi về sỉ số lớp ít, phụ cấp giảng viên cao, số tiết dạy ít. Trong khi nhiều trường trong nước cũng như tại trường ĐHCNTP TP.HCM, khía cạnh đánh giá sinh viên chủ yếu thi giữa kỳ, tiểu luận, thi cuối kỳ.

Về hướng nghiên cứu tiếp theo, những nhà quản lý các trường đại học nói chung, trường ĐH Công Nghiệp TP.HCM nói riêng có thể tiếp tục nghiên cứu mở rộng đối tượng là đội ngũ giảng viên, cán bộ quản lý, nhân viên hành chánh cũng như những cơ chế, chính sách liên quan ảnh hưởng trực tiếp hoặc gián tiếp sự hài lòng của sinh viên.

\section{TÀI LIỆU THAM KHẢO}

[1] Ashim Kazastha (2011), "A Study of graduate student satifaction towards service quality of universities in Thailan”, Masters in Business Administration, Webster University.

[2] Becket, N. \& Brookes, M. (2006). Evaluating quality management in university departments. Quality Assurance in Education, 14(2), 123-42. 
[3] Bitner, M.J. \& Zeithaml, V.A. (1996), “Services Marketing”, New York: McGraw-Hill.

[4] Brochado, A. (2009). Comparing Alternatives Instruments to Measure Services Quality in Higher Education. Quality in Higher Education, 17 (2), 1-30.

[5] Firdaus, A. (2005). The development of HEdPERF: a new measuring instrument of service quality of higher education sector. Paper presented at the Third Annual

[6] Hoàng Trọng \& Chu Nguyễn Mộng Ngọc (2008), Phân tích dũ liệu nghiên cưu với SPSS, NXB Thống Kê.

[7] Nguyễn Đình Thọ \& ctg (2003), Đo lường chất lượng dịch vụ vui chơi giải trí ngoài trời tại TP.HCM, Đề tài nghiên cứu khoa học, MS: CS2009-19, Trường Đại học Kinh Tế TP.HCM.

[8] Nguyễn Đức Chính (2002), Kiểm định chất luợng trong giáo dục đại học, Nxb ĐHQG Hà Nội, Hà Nội.

[9] Nguyễn Thành Long (2006), sủ dụng thang đo SERVPERF để đánh giá chất luợng đào tạo DH tại truờng $Đ H A G$-Báo cáo nghiên cứu khoa học trường ĐHAG.

[10] Nguyễn Thúy Quỳnh Loan \& Nguyễn Thị Thanh Thoản (2005), "Đánh giá chất luợng đào tạo tù góc độ cựu sinh viên của Truờng Đại học Bách Khoa TP.HCM', Kỷ yếu hội thảo đảm bảo chất lượng trong đổi mới giáo dục đại học, tr.305 - 319 .

Ngày nhận bài: 14/03/2017

Ngày chấp nhận đăng: 09/11/2017 